\title{
ARTIGOS
}

\section{CONSTRUÇÃO E VALIDAÇÃO DE UMA ESCALA DE VALORES SOCIOMORAIS}

MARIALVA ROSSI TAVARES •

MARIA SUZANA DE STEFANO MENIN •

PATRÍCIA UNGER RAPHAEL BATAGLIA•

TELMA PILEGGI VINHA •

LUCIENE REGINA PAULINO TOGNETTA •

RAUL ARAGÃO MARTINS • ADRIANO MORO

\section{RESUMO}

A presente pesquisa teve como objetivo construir e validar uma escala de valores sociomorais que mensurou a presença e o modo de adesão aos valores de justiça, respeito, solidariedade e convivência democrática em estudantes e professores da educação básica em escolas públicas e privadas de São Paulo (10.011 participantes). A metodologia envolveu a elaboração de histórias com alternativas pró e contravalor em três níveis de perspectiva social, a aplicação de questionário na amostra e o processamento dos dados com o uso da Teoria de Resposta ao Item - TRI -, segundo o modelo para itens politômicos. Como resultados, apresentam-se as classificações dos participantes em níveis estabelecidos por valor e discutem-se as implicações educacionais da pesquisa.

\section{VALORES MORAIS • VALORES SOCIAIS • TEORIA DA RESPOSTA AO ITEM • JUÍZO MORAL}

\section{CONSTRUCTION AND VALIDATION OF A SOCIO-MORAL VALUES SCALE}

\section{ABSTRACT}

This study aimed to construct and validate a socio-moral values scale to measure the presence and commitment to the values of justice, respect, solidarity and democratic coexistence of students and teachers in Basic Education in public and private schools in São Paulo (10,011 participants). The methodology involved the development of stories with pro and con alternatives at three levels of social perspective, as well as the application of a questionnaire to the sample and data processing using the Item Response Theory model for polytomous items. As a result, the classification of participants in standards set by value is presented and some educational implications of the research are discussed. 


\section{CONSTRUCTION ET VALIDATION D'UNE ÉCHELLE DE VALEURS SOCIO-MORALES}

RÉSUMÉ

La présente recherche a eu pour objectif de construire et de valider une échelle de valeurs socio-morales qui a mesuré la présence et le mode d'adhésion aux valeurs de justice, de respect, de solidarité et de coexistence démocratique chez les étudiants et les enseignants du primaire et du secondaire dans des établissements publics et privés de São Paulo (10.011 participants). La méthodologie a englobé l'élaboration de récits avec alternatives pour et contre-valeur à trois niveaux de perspective sociale, l'application de questionnaires à cet échantillon de personnes et le traitement de données basé sur la Théorie des Réponses aux Items - TRI -, d'après le modèle pour items polytomiques. Comme résultats, les classifications des participants en fonction des niveaux établis par la valeur sont presentées et les implications éducationnelles de la recherche sont discutées.

VALEURS MORALES • VALEURS SOCIALES • THÉORIE DES RÉPONSES AUX

ITEMS • JUGEMENT MORAL

\section{CONSTRUCCIÓN Y VALIDACIÓN DE UNA ESCALA DE VALORES SOCIOMORALES}

RESUMEN

Este estudio tuvo el objetivo de construir y validar una escala de valores sociomorales que mide la presencia y la adhesión a los valores de justicia, respeto, solidaridad y convivencia democrática en los estudiantes y profesores de educación básica en las escuelas públicas y privadas en São Paulo (10.011 participantes). La metodología consistió en la elaboración de historias con alternativas favorables y contrarias en tres niveles de la perspectiva social, en la aplicación del cuestionario en la muestra $y$ en el procesamiento de los datos con el uso de la Teoría de Respuesta al Ítem en el modelo para los artículos politómicos. Como resultado de ello, presenta las clasificaciones de los participantes en niveles establecidos por el valor y discute algunas implicaciones educativas de la investigación. 
ESTE ARTIGO, APRESENTA-SE UMA PESQUISA QUE TEVE COMO OBJeTIVO GERAL A construção, a testagem e a validação de um instrumento capaz de avaliar o modo de adesão a valores sociomorais em crianças do segundo ciclo da escola fundamental, em adolescentes do ensino médio e em professores de educação básica. Os valores tratados na escala foram os seguintes: justiça, respeito, solidariedade e convivência democrática.

O texto foi organizado da seguinte forma: em primeiro lugar, na introdução, se esclarecem a motivação do trabalho com o tema "valores sociomorais" e com esses valores citados em particular; os tipos de perspectivas sociomorais descritas por Kohlberg (1981), nas quais foram baseadas as alternativas dos itens do instrumento e, por fim, são

Pesquisa financiada pela Fundação de Amparo à Pesquisa do Estado de São Paulo - Fapesp processo n. 2013/09398-7

Agradecemos ao prof. Dalton Francisco de Andrade por sua participação nesta pesquisa orientando o procedimento da aplicação da teoria de resposta ao item Agradecemos também a Raquel da Cunha Valle e a Miriam Bizzocch pelo processamento estatístico dos dados. retomados outros instrumentos de avaliação do juízo moral, evidenciando o diferencial da escala agora apresentada. Em seguida, na metodologia, descreve-se a construção da escala em cada etapa do processo. Apresentam-se, então, os resultados da aplicação, que visou à validação do instrumento e, por fim, discutem-se algumas implicações educacionais da pesquisa.

O tema "valores" tem sido alvo de várias reflexões por autores brasileiros e estrangeiros, especialmente em um momento em que se questiona quais valores são fundamentais, ou mesmo, se há valores universais na pós-modernidade. Expressões como "crepúsculo do dever" (LIPOVETSKY, 2010) e "renascimento da moralidade" (BAUMAN, 1998) têm sido debatidas em busca de explicações e até de encaminhamentos 
para a sociedade atual, na qual alguns valores morais, como a generosidade e o respeito mútuo, passam a ser vistos em crise, em nome da ascensão de outros valores pessoais momentâneos, como a fama e a aparência física. No Brasil, autores que estudam desenvolvimento e educação moral (LA TAILLE; MENIN, 2009; LA TAILLE, 2006, 2009; MENIN, 2002; MENIN et al., 2010; TOGNETTA; VINHA, 2007; TOGNETTA, 2003; 2006; D’AUREA-TARDELI, 2006, 2011; ARAÚJO; PUIG; ARANTES, 2007; ARAÚJO, 2008; ARAÚJO; ARANTES, 2009; VINHA, 2000, 2003), ou que estudam as relações entre ética e educação (GOERGEN, 2001, 2007; LOMBARDI; GOERGEN, 2005; SILVA, 2010) também têm apontado essa crise dos valores morais.

Se tal crise tem sido verificada na sociedade em geral, também muito se tem falado a respeito da crise de valores na escola e seu papel na educação moral (ZECHI, 2008; SILVA, 2004; SPOSITO, 2001; MENIN et al., 2010; MARTINS; SILVA, 2009; TREVISOL, 2009). É inegável a importância das instituições formadoras no oferecimento de ambientes mais ou menos favorecedores para a constituição de sujeitos autônomos. Piaget (1994 [1932]) apontou que a cooperação é condição necessária para a reciprocidade, da qual, por sua vez, depende a autonomia. Ora, são alguns valores implícitos na cooperação - a justiça, o respeito mútuo, a solidariedade e a convivência democrática - que se referem a um compromisso com o coletivo e, ao mesmo tempo, que implicam deveres para consigo próprio, no sentido ético relacionado à vida que a pessoa escolhe viver (LA TAILLE, 2009).

Tocar no tema "valores sociomorais" pede, ainda, uma reflexão a respeito da posição epistemológica adotada com relação ao universalismo versus o relativismo ético. Assim como Kohlberg (1981), consideramos inegável o relativismo cultural, que não se confunde com a falácia naturalista de afirmar o dever ser a partir do ser. Conforme Vazquez (1993), valores correspondem a atos ou produtos humanos e incluem ações realizadas livre e conscientemente, às quais se possa atribuir uma responsabilidade moral. Lima (2012) ressalta que valores são critérios de orientação que guiam ações e expressam cognitivamente suas necessidades básicas. Assim, é compreensível que, de acordo com determinantes históricos e culturais, alguns povos elejam como mais importantes alguns valores e outros, valores diferentes. A universalidade defendida por Kohlberg (1981) consiste nas formas hierárquicas de adesão a tais valores evidenciadas pela análise dos juízos morais emitidos frente a dilemas. Tais juízos foram classificados pelo autor como pré-convencionais, convencionais e pós-convencionais, e um dos critérios utilizados para caracterizar os juízos nesses níveis foi a análise da perspectiva social adotada.

Para definir perspectiva social, ou percepção social, Kohlberg (1992, p. 186) considerou "como as pessoas veem as outras, interpretam seus 
pensamentos e sentimentos e consideram o papel e o lugar que ocupam em sociedade". O autor ainda sublinhou que "o desenvolvimento da percepção social de um estágio, ocorre antes, ou é mais fácil que o desenvolvimento do estágio paralelo de juízo moral” (KOHLBERG, 1992, p. 186).

São descritos por Kohlberg (1992) três modos de adesão a valores, de acordo com as perspectivas sociais adotadas: uma perspectiva individualista, ou egocentrada, outra centrada nas relações grupais, familiares e em normas sociais convencionais, nomeada como sociocêntrica e, finalmente, outra perspectiva, chamada moral, mais descentrada socialmente e baseada em contratos estabelecidos democraticamente por procedimentos justos. Esta última perspectiva é ainda caracterizada por buscar a garantia da dignidade do ser humano, uma vez que se refere a seguir leis ou regras baseadas em princípios universalizáveis, erigidos por qualquer ser racional de acordo com sua própria vontade.

$\mathrm{Na}$ escolha dos valores que constituiriam o instrumento desta pesquisa, consideramos, ainda do ponto de vista teórico, as contribuições de Piaget (1994 [1932]) e de Kohlberg (1992). Do ponto de vista da legislação educacional brasileira, consideramos os Parâmetros Curriculares Nacionais - PCN - (BRASIL, 1998), que, ao pautarem a ética como um dos temas transversais na educação, elegeram os valores de respeito mútuo, justiça, solidariedade e diálogo como os mais relevantes para o desenvolvimento moral de crianças e adolescentes. No instrumento aqui apresentado, optou-se por substituir o diálogo por convivência democrática por se compreender que o diálogo é um operador mais do que um valor. Esse operador é essencial para a convivência social democrática, mas não é, em si, um valor.

Além de constarem nos PCN, tais valores estão sempre presentes nos objetivos dos projetos político-pedagógicos e nas falas dos professores. Há uma busca por propostas e projetos que os desenvolvam; contudo, raramente essas intervenções são avaliadas de forma a identificar a eficácia ou as contribuições de tais ações.

Bataglia, Shimizu e Lepre (2010) realizaram um levantamento dos instrumentos de avaliação de aspectos relativos à moralidade em uso no Brasil. Desde que a "Entrevista de juízo moral" - MJI - (Moral judgment interview) foi desenvolvida em sua forma final por Colby e Kohlberg (1987), outros instrumentos mais objetivos foram propostos: o Defining issue test - DIT - (REST, 1986), o Socio-moral reflection objective measure - SROM (GIBBS; ARNOLD; BURKHART, 1984), o Problem identification test-PIT-(HEBERT et al., 1990) e o Moral competence test-MCT - (LIND, 2015). Cada instrumento abarca um aspecto diferente da moralidade. A MJI e o SROM se propõem a avaliar o estágio de desenvolvimento do juízo moral; o DIT avalia, principalmente, a proporção de respostas do esquema pós-convencional preferidas pelo sujeito; o PIT avalia a sensibilidade ética dos sujeitos e o MCT afere a eficácia de intervenções educacionais sobre a competência 
moral de grupos. Todos os instrumentos citados trabalham com valores, entretanto nenhum deles tem a proposta de avaliar especificamente a adesão a valores.

Estudiosos no Brasil têm identificado o desenvolvimento de determinados valores morais, como a justiça, a solidariedade, o diálogo, a generosidade; mas o fazem utilizando instrumentos que trabalham com um valor ou outro de modo separado. São exemplos desses tipos de trabalho os estudos de Tognetta $(2003,2009)$ sobre as noções de solidariedade em crianças, nos quais foram usadas histórias que contrapunham a solidariedade ao sucesso, ou ao prazer momentâneo, ou à obediência à autoridade. Vinha (2000, 2003), Vicentin (2009), Frick (2011), Tognetta e Vinha (2007) relacionaram a qualidade dos ambientes mais ou menos cooperativos na escola com o desenvolvimento de habilidades para negociação em conflitos, o diálogo, a cooperação, a solidariedade e o respeito, por meio do uso de histórias e entrevistas.

Tognetta (2009) pesquisou a construção da generosidade em crianças em relação à imagem de si e dos outros. La Taille (2006) também realizou uma mensuração de valores em adolescentes. Em várias dimensões analisadas (valores na relação do indivíduo com instituições da sociedade, na relação com os outros, consigo mesmo), adolescentes foram questionados a respeito da importância dessas instituições em suas vidas, do grau de confiança, ou a respeito de quanto essas dimensões e seus componentes influenciavam seus valores. Menin (2007, 2002) tem trabalhado a noção de injustiça em adolescentes, utilizando questões abertas ou associações livres sobre a palavra injustiça, ou, ainda, sobre relatos de casos de injustiça em geral e na escola.

Mais do que avaliar o modo de adesão a valores, vários estudos construtivistas têm enfatizado a importância de análise do contexto como variável determinante. Selman (1980) e Selman et al. (1986) ressaltam que as crianças podem mostrar uma estratégia mais evoluída numa situação e outra, menos avançada, em outro momento, em função das possibilidades e exigências do contexto. Ao mensurar valores, também é preciso considerar como a adesão a estes pode ser influenciada pela forma como eles são percebidos pelos sujeitos frente ao contexto em que vivem; por exemplo, quando confrontados com valores oponentes - ou contravalores - ou quando apresentados em diferentes espaços (lócus) como família, escola, ou internet, ambientes sociais diversos. Tais fatores foram considerados na elaboração do instrumento aqui apresentado, além de variáveis sociais e situacionais que podem influenciar o modo de adesão aos valores, tais como: nível educacional dos pais, classificação econômica, série escolar, idade e gênero dos alunos e características das relações sociais na escola e na família.

Descreveremos, a seguir, a metodologia do trabalho realizado pela equipe, que teve como questão central a seguinte pergunta: qual 
o nível de perspectiva sociomoral adotada por crianças, adolescentes e professores ao se depararem com problemas que envolvem os valores justiça, respeito, solidariedade e convivência democrática?

\section{METODOLOGIA}

\section{A ELABORAÇÃO DE ITENS PARA O QUESTIONÁRIO}

A primeira etapa para a construção do instrumento de pesquisa utilizado nesta investigação, um questionário com questões na forma de histórias, foi a definição dos valores e seus descritores. Isso se deu por meio da elaboração de uma matriz dos valores de justiça, respeito, solidariedade e convivência democrática. Para a elaboração da matriz, usamos como referenciais principais os PCN (BRASIL, 1998), em seus cadernos sobre ética, e conceitos da Psicologia da moralidade de Piaget (1994 [1932]) e de Kohlberg (1992).

Ilustramos, a seguir, uma parte da matriz elaborada para o valor de solidariedade:

\section{Conceito:}

Ser solidário é, efetivamente, além do respeito, partilhar de um sentimento de interdependência, reconhecer a pertinência a uma comunidade de interesses e de afetos - tomar para si questões comuns; responsabilizar-se pessoal e coletivamente por elas. (BRASIL, 1998, p. 104)

\section{Exemplos de descritores:}

1. Identificar que a busca pela realização do ideal de solidariedade é de todos.

2. Cooperar, de forma generosa, com outros, próximos ou não, buscando o bem deles, independentemente do benefício próprio.

3. Compartilhar sentimentos e conhecimentos com outros, visando ao benefício de todos e de si mesmo.

Exemplos de contravalores:

1. Individualismo; competição/corporativismo; omissão/ indiferença.

2. Cepticismo ou descrédito em relação à busca do bem comum.

Entendemos como contravalores atitudes que se opõem à adoção dos valores e procuramos destacar, também na matriz, contravalores mais específicos para cada valor dentre os quatro estudados.

A elaboração dos descritores dos valores e de seus contravalores nos auxiliou na construção dos itens em pequenas histórias que compuseram o questionário. Escrevemos cerca de trinta itens para cada um dos 
quatro valores eleitos. Eles foram elaborados na forma de situações-problema, baseando-se em cenas do cotidiano das pessoas (crianças, adolescentes ou professor) e que poderiam ocorrer em diferentes espaços, como família, escola, internet e ambientes sociais diversos. As histórias terminavam com uma frase a completar ou uma questão sobre o que se deveria fazer, seguidas de cinco alternativas de resposta. O participante da pesquisa deveria ler o item e escolher uma dentre as alternativas. Três delas apresentavam-se favoráveis ao valor focalizado no item e duas apresentavam-se contrárias a ele; ou seja, basearam-se num contravalor.

Além de as alternativas dentro dos itens apresentarem posições em prol dos valores ou contra eles, também foram constituídas em níveis que evidenciavam o modo de adesão ao valor, entendido, nesta pesquisa, como a perspectiva social na qual o valor é usado.

Desse modo, dentre as cinco alternativas oferecidas para cada item no questionário, três afirmavam o valor focado na história em perspectivas sociomorais de níveis crescentes de descentração (P1 egocêntrica, P2 sociocêntrica e P3 moral) e duas alternativas afirmavam um contravalor, o fazendo, também, num nível egocêntrico (C1) ou sociocêntrico (C2).

Ilustramos, a seguir, um item do questionário com uma história sobre solidariedade. Para facilitar a identificação da natureza das alternativas, elas estão colocadas numa ordem que vai dos contravalores à afirmação dos valores em níveis crescentes de perspectiva social. No questionário, todas as alternativas foram sempre randomizadas.

\footnotetext{
Eugênio é o melhor aluno de Biologia da sala. Há, em sua classe, um aluno que acabara de ser transferido e que tem dificuldade nesta disciplina. Como os exames estão próximos, ele pediu ajuda para Eugênio, mas este havia sido convidado pelos amigos para ir jogar futebol, como sempre faz nas tardes de quinta-feira com a turma. O problema é que era justamente quinta-feira. Você acha que Eugênio deveria...

C1 - ir para o futebol com seus amigos; era quinta-feira e estava acostumado a fazer isso.

C2 - ir ao futebol, porque ele já havia combinado com a turma.

P1 - ajudar o aluno novo com os estudos em troca de ele o ajudar em outra matéria.

P2 - ajudar o aluno novo com os estudos, porque sabe que é o que se deve fazer.

P3 - ajudar o aluno novo com os estudos, pois ele precisa de explicações nesta disciplina.
} 
No exemplo anterior, C1 e C2 são respostas contravalor nos níveis de perspectiva social egocêntrica e sociocêntrica, respectivamente, e P1, P2 e P3 são respostas pró-valor egocêntrica, sociocêntrica e moral. ${ }^{1}$

Os itens construídos foram submetidos a especialistas em psicometria e em desenvolvimento moral, que procederam a novas análises do material para ajuste final de seu conteúdo. Após essa revisão, foi realizada uma pré-testagem da escala em cerca de 900 participantes, entre alunos do ensino fundamental (segundo ciclo), do ensino médio e professores da educação básica. Nessa testagem, foi também aplicada uma versão do questionário com questões abertas. As respostas espontâneas dos participantes, cerca de 300, serviram para a verificação da qualidade das alternativas propostas nas questões fechadas, principalmente quanto à expressão dos níveis de perspectiva social.

Finalmente, os itens construídos compuseram questionários que foram aplicados em alunos do ensino fundamental de $5^{\circ}$ ao $9^{\circ}$ ano, adolescentes do ensino médio e professores da educação básica, em 75 escolas públicas e privadas, a maioria do estado de São Paulo. O número de participantes foi de 4503 crianças, 4193 adolescentes e 1315 professores, num total de 10.011 pessoas. O questionário sobre os quatro valores foi aplicado em cadernos compostos de duas partes: uma, constituída por questões caracterizando o perfil dos respondentes (características gerais dos participantes e questões sobre relações sociais na escola e na família), e outra, com as questões na forma de pequenas histórias sobre os valores. Os cadernos para as crianças continham 16 questões e focaram dois valores em cada caderno. Os cadernos para adolescentes apresentavam 20 questões, também com dois valores em cada caderno, e os de professores continham 25 questões e focavam três valores por vez.

\section{O MODELO ESTATÍSTICO PARA GERAR A ESCALA}

Nesta pesquisa, um dos modelos da Teoria da Resposta ao Item - TRI - (ANDRADE; TAVARES; VALLE, 2000) foi escolhido para a construção das escalas por meio das quais os participantes poderiam ser classificados em níveis de adesão aos valores. Cada valor foi considerado uma dimensão única e tratado separadamente, de maneira que foram construídas quatro escalas, uma para cada valor: justiça, respeito, solidariedade e convivência democrática.

A TRI permite o estudo de variáveis latentes ou, como costumamos chamar, traços latentes, isto é, que não podem ser diretamente observados ou medidos. Tal como certas formas de conhecimento

Mais exemplos de histórias se encontram em Tavares (2013) ou Menin, Bataglia e Moro (2013); ambos artigos da revista Estudos em Avaliação Educacional, São Paulo v. 24 , n. 56 , set./dez. 2013 ou características de personalidade, entendemos que a adesão a valores também pode ser medida indiretamente, como um traço latente. Para a medida desse traço, usamos a escolha dos participantes em relação às alternativas das histórias sobre valores que perguntavam o 
que se deveria fazer. Neste trabalho, utilizamos o Modelo de resposta gradual de Samejima apropriado para respostas politômicas (ARAÚJO; ANDRADE; BORTOLOTTI, 2009), como é o caso dos itens utilizados que continham cinco possibilidades de respostas (as alternativas C1, C2, P1, P2, P3) e não apenas uma resposta certa e outra errada.

Essa metodologia estatística se tornou mais conhecida entre nós e é utilizada em seu modelo dicotômico nos exames nacionais de avaliação, como o Sistema de Avaliação da Educação Básica - Saeb - e o Exame Nacional do Ensino Médio - Enem. Como explicam Andrade, Tavares e Valle (2000), Karino e Andrade (2011) e Tavares (2013), a opção pela TRI se deve à possibilidade de um instrumento de investigação poder ser usado várias vezes, modificando-se parte de seus itens, sem que os mesmos percam sua validade, e desde que os itens estejam mensurando as mesmas dimensões. Como explicamos anteriormente, os participantes desta pesquisa, crianças, adolescentes e professores, responderam a cadernos com um número diferente de itens de cada valor e, entre esses grupos, houve itens comuns, ou itens de ligação, que permitiram a colocação desses grupos nas mesmas escalas de valores (VALLE, 2001).

A TRI parte do princípio de que, quanto maior a proficiência do respondente em relação ao traço latente que está sendo avaliado, maior sua probabilidade de atingir níveis mais altos na escala. Fazendo um paralelo com nossa pesquisa e considerando o "nível de adesão a valores" como traço latente, podemos afirmar que, quanto melhor for a formação ética/moral do respondente em relação aos valores avaliados, maior será a probabilidade de este atingir o nível da escala de valores que corresponde à perspectiva social propriamente moral.

Para a construção da escala, o processamento da TRI levou em conta a categorização das alternativas nos níveis de perspectiva social (C1, C2, P1, P2, P3). Neste estudo, inicialmente fixamos como 100 a média do grau de adesão ao valor do grupo de crianças e em 25 o desvio padrão. Assim, as probabilidades de escolha dos respondentes em relação às alternativas de cada item foram calculadas em intervalos de 25 em 25 pontos, ou seja, em intervalos correspondentes a um desvio padrão.

A segunda etapa na construção da escala foi o estabelecimento de critérios a partir dos quais se pudessem identificar os pontos em que um indivíduo deixaria de pertencer a um modo de adesão ao valor e passaria para outro modo; por exemplo, o ponto em que diminuiria a probabilidade de ser pró-valor na perspectiva egocêntrica (P1) e aumentaria a probabilidade de ser pró-valor na perspectiva sociocêntrica (P2).

Para a definição desses níveis de adesão ao valor, foi estabelecido como critério tomar-se como ponto de partida a posição mais alta da perspectiva sociomoral que denominamos de nível IV (modo de adesão em perspectiva moral propriamente dita). Convencionamos, para esse 
nível IV de adesão (escolha das alternativas P3), que seu intervalo seria aquele em que 100\% dos itens tivessem uma alta probabilidade de adesão ao valor na perspectiva sociocêntrica (escolhas em P2) e pelo menos $75 \%$ deles tivessem alta probabilidade de adesão ao valor em perspectiva propriamente moral (escolhas em P3). Ou seja, pessoas em nível IV seriam aquelas que escolheriam alternativas, no mínimo, em P2 (perspectiva sociocêntrica), e não em nível menor que este, e que teriam, também, 75\% de suas escolhas de alternativas em P3 (nível de perspectiva moral propriamente dita).

Esse mesmo critério estendeu-se para as demais alternativas relativas às perspectivas sociomorais estudadas na pesquisa $(\mathrm{C} 1, \mathrm{C} 2, \mathrm{P} 1, \mathrm{P} 2)$.

O Quadro 1 ilustra os critérios estabelecidos para cada um dos quatro níveis, que foram assim definidos.

\section{QUADRO 1}

CRITÉRIOS PARA A DEFINIÇÃO DOS NÍVEIS DE ADESÃO AOS VALORES

\begin{tabular}{|l|l|}
\hline \multicolumn{1}{|c|}{ NÍVEL DE ADESÃO AO VALOR } & \multicolumn{1}{c|}{ CRITÉRIOS PARA DETERMINAÇÃO DOS NÍVEIS } \\
\hline IV (P3) - Perspectiva moral & $\begin{array}{l}\text { Todos os itens devem atingir P2 e, pelo menos, } \\
75 \% \text { deles atingir P3 }\end{array}$ \\
\hline III (P2) - Perspectiva sociocêntrica & $\begin{array}{l}\text { Todos os itens devem atingir P1 e, pelo menos, } \\
75 \% \text { deles atingir P2 }\end{array}$ \\
\hline II (PI) - Perspectiva egocêntrica & $\begin{array}{l}\text { Todos os itens devem atingir C2 e, pelo menos, } \\
75 \% \text { deles atingir P1 }\end{array}$ \\
\hline I (C2) - Contravalor & $\begin{array}{l}\text { Todos os itens devem atingir C1 e, pelo menos, } \\
75 \% \text { deles atingir C2 }\end{array}$ \\
\hline
\end{tabular}

Fonte: Elaboração dos autores.

Do ponto de vista do desenvolvimento do raciocínio moral, Colby e Kohlberg (1987) sugerem, a partir de pesquisas em diversas populações e interculturais, que, no mínimo, 67\% das respostas de uma pessoa devem estar num determinando estágio de desenvolvimento (dentre os seis estabelecidos pelo autor nos três níveis: pré-convencional, convencional e pós-convencional) para que se possa afirmar que essa pessoa estaria nesse estágio. Nossa pesquisa mensura, no entanto, não propriamente o raciocínio moral, ${ }^{2}$ mas a perspectiva social em que uma escolha estágio de raciocínio moral que a pessoa considera que é certo (que pode incluir leis e normas, consciência papéis dos afetos pessoais autoridade, direitos civis, contrato, confiança, valor da vida, direitos e valores de propriedade, verdade amor e sexo), as razões que há para atuar corretamente e que compõem os juizos de justiça; e a perspectiva social do estágio (KOHLBERG, 1992) sobre valores é feita, ou seja, o posicionamento em relação a si e aos outros utilizado pela pessoa ao fazer uma escolha entre possíveis atitudes morais. Para Kohlberg (1992), como explicamos, essa perspectiva social nos julgamentos morais é mais fácil e obtida mais cedo que o raciocínio moral propriamente dito. Assim, decidimos por uma porcentagem mais alta, ou seja, 75\%, como critério de definição do nível de adesão ao valor. Com esse critério, como dissemos, uma pessoa necessitaria ter 75\% de suas escolhas em alternativas P3 para ser considerada em nível IV.

Assim, com o processamento da TRI, tornaram-se possíveis tanto a identificação dos níveis de adesão a cada valor relativos a ser pró ou 
contra o valor nas três perspectivas sociais (egocêntrica, sociocêntrica, moral) como a distribuição dos participantes da pesquisa em cada nível. O primeiro nível, nível I, correspondeu ao posicionamento de contravalor, que agrupou as maiores probabilidades de escolhas de alternativas dos itens em C1 e C2; o nível II correspondeu ao modo de adesão ao pró-valor na perspectiva social egocêntrica, agrupando as probabilidades maiores de escolhas de alternativas P1; o nível III de adesão, numa perspectiva social sociocêntrica, agrupou as alternativas P2, e o nível IV, de adesão ao valor numa perspectiva moral propriamente dita, agrupou as alternativas P3.

Construídas as escalas a partir da análise das alternativas dos itens em cada nível estabelecido, elaboramos uma descrição das respostas nele predominantes e que caracterizavam suas escolhas.

Todo esse procedimento foi adotado para a construção das 4 escalas, sendo uma para cada valor investigado: justiça, solidariedade, respeito e convivência democrática.

\section{RESULTADOS}

Como resultados principais, descrevemos e analisamos a identificação dos níveis de adesão a cada valor nas três perspectivas sociais (egocêntrica, sociocêntrica, moral) e a resultante distribuição dos participantes em seus três grupos - crianças, adolescentes e professores - em cada nível. No entanto, antes de exibir tais dados, apresentamos algumas características do perfil dos participantes.

Consideramos crianças os estudantes de $5^{\circ}$ a $8^{\circ}$ ano do ensino fundamental (4.503 alunos) e adolescentes os do $9^{\circ}$ ano e os do $1^{\circ}$ ao $3^{\circ}$ do ensino médio (4.193 alunos); sendo, a grande maioria deles, da região da Grande São Paulo (estado de São Paulo, Brasil). Esses dois grupos se assemelharam em muitos aspectos. Dividiram-se meio a meio entre meninos e meninas e, em sua grande maioria, pertenciam a escolas públicas (cerca de $80 \%$ de escolas públicas e $20 \%$ de escolas particulares). As classes econômicas mais presentes foram a C1 e B2 (considerando o critério Brasil, 2014), ${ }^{3}$ e o grau de escolaridade do responsável pela família que mais compareceu foi o de ensino médio e o superior incompleto.

Em relação aos professores (1.315 participantes), destacamos que a grande maioria deles foi composta de mulheres, e a faixa etária predominante foi de 26 a 45 anos, com cerca de um quarto entre 46 e 55 anos. As classes socioeconômicas que mais se destacaram foram a B1 e a B2. Os professores frequentaram, na educação básica, predominantemente a escola pública, mas fizeram sua formação superior na escola particular. Quase metade dos professores participantes desta pesquisa apontou ter cursado especializações em nível de pós-graduação (lato sensu). O tempo de serviço dos professores respondentes da pesquisa variou bastante, embora um quarto deles estivesse composto de professores 3 O critério Brasil considera bens materiais e nível de instrução do chefe da família para classificar as famílias em classes econômicas. Em 2014, a população da Grande São Paulo ficou distribuída nas seguintes classes: A1 (O,3\%); $A 2$ (4,7\%); B1 (11,2\%); B2 (25,5\%); C1 (29\%); C2 $(19,8 \%)$; D e E ( $9,5 \%)$. 
iniciantes. A maioria dos professores não exerceu outra função a não ser a de docente. Em relação a cursos de formação continuada sobre valores, menos de um quarto apontou ter feito algo nesse sentido.

Foram apresentadas, ainda, outras perguntas dentro do perfil, tanto para estudantes como para professores, sobre o contexto vivido na escola e na família. As questões referiram-se a sentimentos e à qualidade das relações interpessoais entre adultos e estudantes e entre os alunos na instituição escolar, ao modo como professores lidavam com as infrações dos estudantes, às agressões presenciadas, às formas de relacionamento em casa quanto à existência de apoio, punição e contrato, às percepções sobre autoestima na escola, na família e entre amigos e também aos usos da internet. Contudo, em virtude do espaço restrito, optamos, neste trabalho, por não enfocar os resultados das relações estudadas entre essas variáveis e as médias de cada valor.

Ao analisarmos as respostas de todos os respondentes, percebemos que, como os professores estão em momentos diferentes do desenvolvimento moral em relação aos demais participantes, concentrando-se em níveis mais avançados, a aplicação dos critérios para a definição dos níveis foi feita de forma separada para as duas populações. Para os adultos, foi usado o conjunto completo das histórias do questionário, ao passo que, para as crianças e para os adolescentes, não foram computadas as histórias respondidas pelos professores. Visamos, assim, a eliminar a influência dos adultos na distribuição das crianças e dos adolescentes entre os níveis da escala. O posicionamento dos níveis de adesão aos valores diferiu para crianças e adolescentes, por um lado, e para professores, por outro. Nestes últimos, exigiu-se uma pontuação mais alta de adesão aos valores para que os níveis pró-valor se iniciassem.

TABELA 1

ESTATÍSTICAS DA VARIÁVEL ADESÃO AO VALOR DE SOLIDARIEDADE PARA CRIANÇAS, ADOLESCENTES E PROFESSORES

\begin{tabular}{l|c|c|c|c|c}
\hline POPULAÇÃO & $\mathbf{N}$ & MÉdIA & MÍNIMO & MÁXIMO & $\begin{array}{c}\text { DESVIO } \\
\text { PADRÃO }\end{array}$ \\
\hline Crianças & 2217 & 100,0 & 18,0 & 164,1 & 25,0 \\
\hline Adolescentes & 2046 & 111,4 & 27,2 & 172,7 & 23,8 \\
\hline Professores & 643 & 166,7 & 135,2 & 177,4 & 8,4 \\
\hline Total & 4906 & & & \\
\hline
\end{tabular}

Obs.: O N se refere ao número de participantes que responderam aos itens desse valor. Fonte: Dados da pesquisa (elaboração dos autores).

A Tabela 1 apresenta a média, o mínimo, o máximo e o desvio padrão das pontuações de adesão ao valor de solidariedade para crianças, adolescentes e professores. Nela, pode-se notar que a variabilidade das pontuações de crianças e de adolescentes, representadas pelos desvios padrão, é bastante expressiva nesses dois grupos $(25,0$ e 23,8) 
quando comparada à dos professores $(8,4)$, o que indica uma maior homogeneidade na forma de adesão ao valor nestes últimos que entre as crianças e os adolescentes.

Observa-se, também, na Tabela 1, um aumento da estimativa média de adesão ao valor das crianças $(100,0)$ aos adolescentes $(111,4)$ e destes aos professores (166,7); ainda assim, as distribuições das pontuações do grupo das crianças e dos adolescentes guardam semelhanças. Considerando que as crianças desta pesquisa foram alunos do $5^{\circ}$ ao $8^{\circ}$ ano do ensino fundamental e os adolescentes foram do $9^{\circ}$ ano e das três séries do ensino médio, seria esperada uma maior diferença entre as médias de adesão ao valor dentro do que se conceitua como evolução de estágios no desenvolvimento moral (PIAGET, 1994 [1932]; KOHLBERG; 1992).

Apresentamos, a seguir, quatro gráficos com a distribuição dos participantes da pesquisa nos níveis de adesão aos valores de solidariedade, respeito, justiça e convivência democrática com breve descrição de cada um. Cada gráfico é antecedido de uma tabela que indica as estimativas das médias de adesão ao valor e as pontuações mínimas e máximas obtidas, assim como o desvio padrão para cada grupo de participante.

\section{GRÁFICO 1}

DISTRIBUIÇÃO DAS CRIANÇAS, ADOLESCENTES E PROFESSORES PELOS NÍVEIS DE ADESÃO AO VALOR DE SOLIDARIEDADE

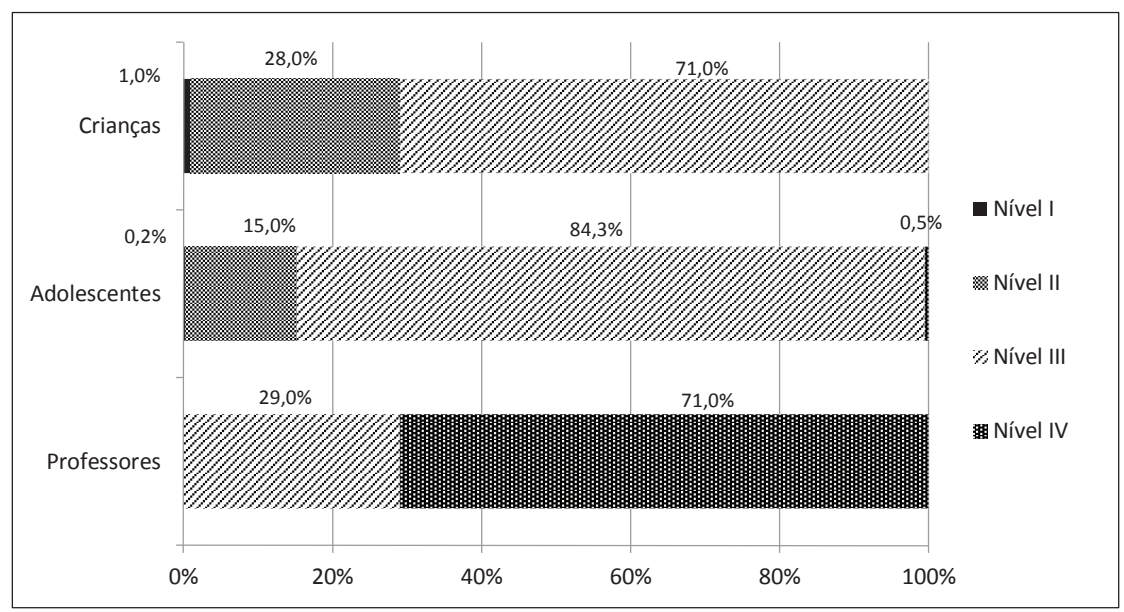

Fonte: Dados da pesquisa (elaboração dos autores).

Pode-se notar, no Gráfico 1, com a distribuição das crianças, adolescentes e professores pelos níveis de adesão ao valor de solidariedade, que, embora as médias dos dois primeiros grupos não tenham apresentado grande diferença, ela existe na forma como eles se distribuíram nos níveis do valor. Os adolescentes apresentam maior desenvolvimento no modo de adesão ao valor em nível III correspondente à perspectiva sociocêntrica $(84,3 \%)$, ao passo que $71 \%$ das crianças estão nesse nível, mas $28 \%$ dessas crianças permanecem no nível II, de modo de adesão ao valor em perspectiva egocêntrica. Apenas 0,5\% dos adolescentes alcança o 
nível IV correspondente ao modo de adesão ao valor em perspectiva propriamente moral. Por outro lado, há 1\% das crianças no nível I, ou seja, posicionando-se contra o valor de solidariedade. No caso desta pesquisa, os professores de educação básica distribuíram-se predominantemente no nível IV, de perspectiva propriamente moral e, em segundo lugar, no nível III, de perspectiva sociocêntrica. Veremos que, apenas no valor de solidariedade, tivemos participantes em nível IV.

Como dissemos, realizamos uma descrição das atitudes predominantes em cada nível para cada valor. Ela se baseou nas escolhas de respostas características para cada nível específico. Como ilustração, mostramos, no Quadro 2, uma descrição dos níveis de adesão para o valor de solidariedade. Nela, e para cada nível, exemplificamos o tipo de resposta que poderia ser dado, utilizando-nos da mesma história citada neste texto, em que um aluno chamado Eugênio deve escolher entre ajudar um colega ou ir jogar futebol.

QUADRO 2

DESCRIÇÃO DOS NÍVEIS DE SOLIDARIEDADE

\begin{tabular}{|c|c|c|}
\hline \multicolumn{3}{|c|}{ DESCRIÇÃO DOS NÍVEIS DE SOLIDARIEDADE } \\
\hline NÍVEIS & DESCRIÇÃO & $\begin{array}{l}\text { RESPOSTAS TÍPICAS PARA } \\
\text { A HISTÓRIA DE EUGÊNIO }\end{array}$ \\
\hline Nível I & $\begin{array}{l}\text { A pessoa opta, na maioria das vezes, por não reconhecer o outro, } \\
\text { omitindo-se ou não sendo solidária por conformidade a uma regra ou à } \\
\text { autoridade. Pode, também, escolher não ser solidário por culpar o outro } \\
\text { por seu infortúnio e porque acredita que cada um é responsável por si. } \\
\text { Contravalores relativos à solidariedade podem predominar, tais como: } \\
\text { individualismo; competição; corporativismo; omissão; indiferença; } \\
\text { ceticismo ou descrédito em relação à busca do bem comum; submissão à } \\
\text { autoridade ou autoritarismo. }\end{array}$ & $\begin{array}{l}\text { C1 - ir para o futebol com seus } \\
\text { amigos; era quinta-feira e } \\
\text { estava acostumado a fazer isso. } \\
\text { C2 - ir ao futebol, porque ele já } \\
\text { havia combinado com a turma. }\end{array}$ \\
\hline Nível II & $\begin{array}{l}\text { É mais frequente a opção da pessoa pela solidariedade, principalmente } \\
\text { por interesse próprio, para manter uma boa relação com o próximo, } \\
\text { por reciprocidade simples (pagar o bem com o bem), para evitar } \\
\text { consequências negativas (reação contrária do outro, conflitos, vinganças, } \\
\text { ou não ser mal visto), ou, ainda, para obter consequências positivas. }\end{array}$ & $\begin{array}{l}\text { P1 - ajudar o aluno novo com } \\
\text { os estudos em troca de ele o } \\
\text { ajudar em outra matéria. }\end{array}$ \\
\hline Nível III & $\begin{array}{l}\text { A pessoa escolhe a solidariedade, na maioria das vezes, movida por } \\
\text { atender às convenções sociais e por obediência ou manutenção das } \\
\text { regras. Em algumas situações, é a favor da solidariedade embora } \\
\text { encaminhe a questão às autoridades em vez de agir por si própria. Pode } \\
\text { ser solidária diante da ausência de ações da autoridade competente. }\end{array}$ & $\begin{array}{l}\text { P2 - ajudar o aluno novo com } \\
\text { os estudos, porque sabe que é } \\
\text { o que se deve fazer. }\end{array}$ \\
\hline Nível IV & $\begin{array}{l}\text { Neste nível, a pessoa opta, mais fortemente, pela solidariedade, para } \\
\text { atender ao outro ou o coletivo, por buscar a igualdade, ou o bem comum, } \\
\text { por sensibilizar-se pela necessidade do outro, ou, ainda, por compartilhar } \\
\text { sentimentos e perspectivas. }\end{array}$ & $\begin{array}{l}\text { P3 - ajudar o aluno novo com } \\
\text { os estudos, pois ele precisa de } \\
\text { explicações nessa disciplina. }\end{array}$ \\
\hline
\end{tabular}

Fonte: Elaboração dos autores.

Para os demais gráficos de cada valor, por uma questão de espaço, apresentamos apenas uma breve descrição da distribuição dos participantes nos níveis de adesão sem descrever as características de cada nível. 
TABELA 2

ESTATÍSTICAS DA VARIÁVEL ADESÃO AO VALOR DE RESPEITO PARA CRIANÇAS, ADOLESCENTES E PROFESSORES

\begin{tabular}{l|c|c|c|c|c}
\hline POPULAÇÃO & N & MÉDIA & MÍNIMO & MÁXIMO & $\begin{array}{c}\text { DESVIO } \\
\text { PADRÃO }\end{array}$ \\
\hline Crianças & 2266 & 100,0 & 13,0 & 163,9 & 25,0 \\
\hline Adolescentes & 2133 & 117,2 & 39,1 & 176,7 & 24,2 \\
\hline Professores & 667 & 168,9 & 159,1 & 173,4 & 2,4 \\
\hline Total & 5066 & \multicolumn{5}{|l}{}
\end{tabular}

Obs.: O N se refere ao número de participantes que responderam aos itens desse valor.

Fonte: Dados da pesquisa (elaboração dos autores).

A Tabela 2 apresenta a média, o mínimo, o máximo e o desvio padrão das pontuações de adesão ao valor de respeito para crianças, adolescentes e professores. Nela, podemos notar, novamente, que as variabilidades dos grupos de crianças e de adolescentes, em termos do desvio padrão, são muito mais expressivas $(25,0$ e 24,1$)$ que a do grupo de professores $(2,4)$. Isso indica grande concentração das pontuações dos professores em torno de sua média $(168,9)$, tratada aqui como homogeneidade da distribuição.

Igualmente, observa-se uma evolução nas médias crescentes de adesão ao valor de respeito entre crianças $(100,0)$ e adolescentes $(117,2)$ e destes para os professores $(168,9)$.

\section{GRÁFICO 2}

DISTRIBUIÇÃO DAS CRIANÇAS, ADOLESCENTES E PROFESSORES PELOS NÍVEIS DE ADESÃO AO VALOR DE RESPEITO

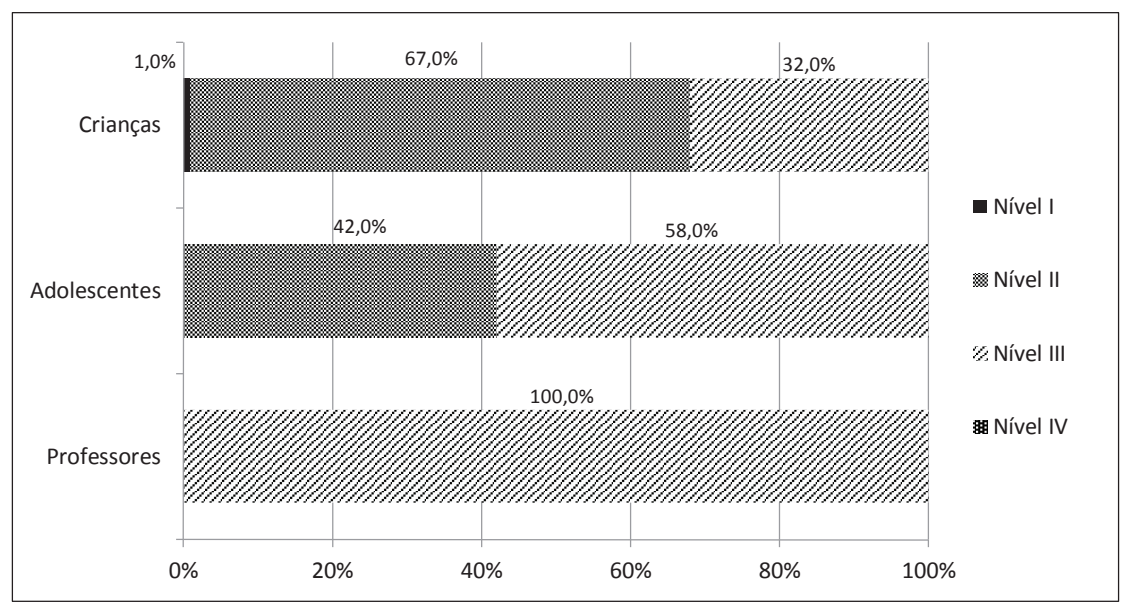

Fonte: Dados da pesquisa (elaboração dos autores).

No Gráfico 2, com a distribuição dos respondentes nos níveis de respeito, observamos que, entre as crianças, há o predomínio da adesão ao valor em nível II (67\%), perspectiva social egocêntrica, ao passo que, nos adolescentes, essa predominância se dá no nível III (58\%), do modo de adesão ao valor em perspectiva sociocêntrica. Já os professores 
mostram-se, em sua totalidade, no nível III (100\%) de adesão em perspectiva social sociocêntrica. Assim, nem crianças, nem adolescentes, nem professores atingem o nível IV de adesão ao valor de respeito em perspectiva propriamente moral. Há, ainda, 1\% das crianças permanecendo em nível I, caracterizado pela escolha de resposta contra o valor de respeito.

Em relação ao valor de justiça, consideramos, nesta pesquisa, três dimensões do conceito: a justiça retributiva, que trata da atribuição de consequências aos atos considerados como infrações (penalidades); a justiça distributiva, que lida com a distribuição de bens, deveres e direitos entre as pessoas e cujos valores maiores são a igualdade e a equidade; e a justiça processual, relacionada às formas de julgamento estabelecidas entre as pessoas. As histórias que compuseram os itens desse valor foram elaboradas contemplando esses três aspectos do conceito. Os resultados, no entanto, apresentam a distribuição dos participantes em relação a todas as questões de justiça, sem separar o tipo de noção mensurado, embora saibamos que essas noções podem se desenvolver de modo diferente e provocar resultados diversos na evolução das etapas do desenvolvimento (PIAGET, 1994 [1932]; MENIN; BATAGLIA; MORO, 2013).

TABELA 3

ESTATÍSTICAS DA VARIÁVEL ADESÃO AO VALOR DE JUSTIÇA PARA CRIANÇAS, ADOLESCENTES E PROFESSORES

\begin{tabular}{l|r|r|r|r|r}
\hline POPULAÇÃO & \multicolumn{1}{|c|}{ N } & \multicolumn{1}{c|}{ MÉDIA } & \multicolumn{1}{c|}{ MÍNIMO } & \multicolumn{1}{c}{ MÁXIMO } & \multicolumn{1}{c}{$\begin{array}{c}\text { DESVIO } \\
\text { PADRÃO }\end{array}$} \\
\hline Crianças & 2266 & 100,0 & 20,4 & 151,1 & 25,0 \\
\hline Adolescentes & 2131 & 108,6 & 39,6 & 155,9 & 20,9 \\
\hline Professores & 1313 & 157,8 & 107,0 & 173,3 & 12,2 \\
\hline Total & 5710 & \multicolumn{5}{|c}{} \\
\hline
\end{tabular}

Obs.: O N se refere ao número de participantes que responderam aos itens desse valor. Fonte: Dados da pesquisa (elaboração dos autores).

Na Tabela 3, as estatísticas das pontuações de adesão ao valor justiça indicam, novamente, por intermédio dos desvios padrões, que a concentração das pontuações dos professores $(12,2)$ em torno de sua média $(157,8)$ é maior do que a de crianças $(25,0)$ e de adolescentes $(20,9)$. Por outro lado, nesse valor, o grupo de professores apresenta um desvio padrão maior do que os apresentados pelos adultos nos demais valores $(8,4 ; 2,4$ e 6,9$)$, indicando que nesse caso houve mais diversidade nas respostas dos adultos. Igualmente, observa-se uma evolução entre crianças $(100,0)$ e adolescentes $(108,9)$ e destes para os professores $(157,8)$ nas médias crescentes de adesão ao valor de justiça. 


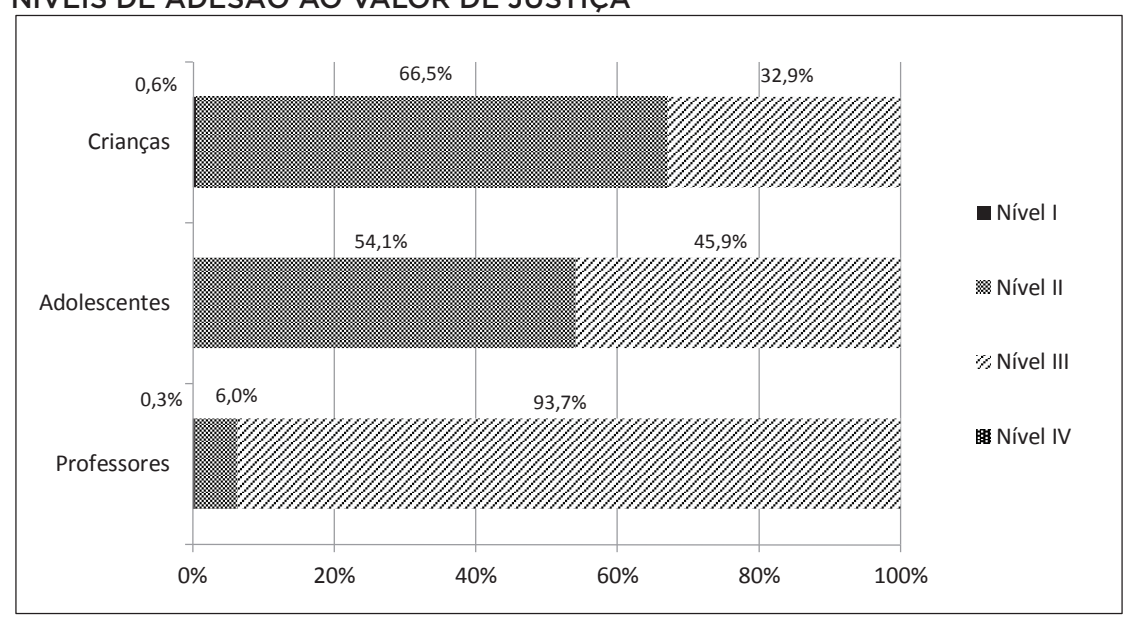

Fonte: Dados da pesquisa (elaboração dos autores).

No Gráfico 3, que ilustra a distribuição de respondentes nos níveis de adesão ao valor de justiça, pode-se observar que há um predomínio das crianças e adolescentes no nível II, de perspectiva social egocêntrica. Os adolescentes apresentam um maior desenvolvimento na adesão a esse valor que as crianças, uma vez que $54,1 \%$ deles estão no nível II e 45,9\%, no nível III, de perspectiva sociocêntrica, ao passo que as crianças apresentam $0,6 \%$ no nível I, referente a contravalor de justiça, 66,5\% no nível II e apenas 32,9\% no nível III.

Nem crianças nem adolescentes alcançaram o nível IV de adesão ao valor de justiça em perspectiva propriamente moral. Os professores estão, em grande maioria, no nível III $(93,7 \%)$ de modo de adesão ao valor em perspectiva sociocêntrica. Na comparação com os Gráficos 1, 2 e 3 e com o Gráfico 4, podemos notar que o valor de justiça se mostrou como de adesão mais difícil para os professores, ou seja, foi o valor em que eles se posicionaram em perspectivas sociais menos descentradas, chegando a ter $6 \%$ de professores em nível II, de perspectiva social egocêntrica, e $0,3 \%$ em contravalor.

TABELA 4

ESTATÍSTICAS DA VARIÁVEL ADESÃO AO VALOR DE CONVIVÊNCIA DEMOCRÁTICA PARA CRIANÇAS, ADOLESCENTES E PROFESSORES

\begin{tabular}{l|c|c|c|c|c}
\hline POPULAÇÃO & N & MÉDIA & MÍNIMO & MÁXIMO & $\begin{array}{c}\text { DESVIO } \\
\text { PADRÃO }\end{array}$ \\
\hline Crianças & 2214 & 100,0 & 20,2 & 155,8 & 25,0 \\
\hline Adolescentes & 2046 & 105,2 & 11,7 & 178,3 & 29,4 \\
\hline Professores & 1310 & 197,2 & 166,1 & 207,7 & 6,9 \\
\hline Total & 5570 & \multicolumn{3}{|c}{} \\
\hline
\end{tabular}

Obs.: O N se refere ao número de participantes que responderam aos itens desse valor. Fonte: Dados da pesquisa (elaboração dos autores). 
Na Tabela 4, as estatísticas das pontuações de adesão ao valor convivência democrática indicam, novamente, por intermédio dos desvios padrão, que a concentração das pontuações dos professores $(6,9) \mathrm{em}$ torno de sua média $(197,2)$ é bem maior do que a de crianças $(25,0)$ e de adolescentes $(29,4)$. Mais uma vez, observa-se uma evolução entre crianças $(100,0)$ e adolescentes $(105,2)$ e destes para os professores $(197,2)$ nas médias crescentes de adesão ao valor de convivência democrática.

GRÁFICO 4

DISTRIBUIÇÃO DAS CRIANÇAS, ADOLESCENTES E PROFESSORES PELOS

NÍVEIS DE ADESÃO AO VALOR DE CONVIVÊNCIA DEMOCRÁTICA

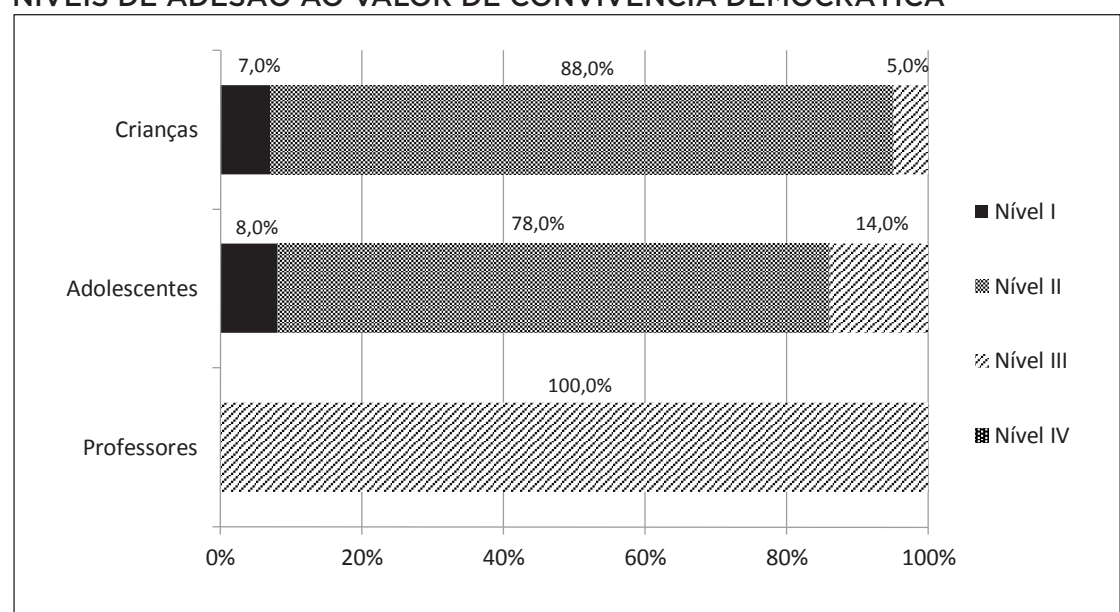

Fonte: Dados da pesquisa (elaboração dos autores).

O Gráfico 4 sobre o valor de convivência democrática mostra que há predomínio tanto das crianças como dos adolescentes no nível II (88\% e 78\%, respectivamente), no modo de adesão ao valor em perspectiva egocêntrica. Há porcentagens semelhantes de crianças e adolescentes no nível I (7\% e 8\%), contravalor, e mais adolescentes no nível III (14\%), de modo de adesão ao valor em perspectiva sociocêntrica, quando comparados às crianças (5\%). Esse valor de convivência democrática mostrou-se, tanto para crianças como para adolescentes, como o valor mais difícil, ou seja, com nenhum indivíduo em nível IV e com a menor distribuição de pessoas em nível III.

Os professores, por sua vez, se mostraram todos no nível III, de perspectiva sociocêntrica, e também não há nenhuma pessoa entre os adultos em nível IV.

Como dissemos, os valores foram tratados como dimensões independentes. Foram calculadas as correlações entre eles e estas não foram elevadas. As maiores correlações foram entre os valores de solidariedade e convivência democrática entre adolescentes $(0,432)$, justiça e solidariedade entre adultos $(0,416)$ e justiça e respeito entre crianças $(0,330)$. 


\section{CONSIDERAÇÕES FINAIS}

Pretendemos, com a construção desse instrumento, contribuir para o uso em pesquisas, inclusive em larga escala, que tenham como objetivo, mais do que identificar a presença de um valor sociomoral em pessoas, constatar também seu grau de adesão. Esperamos, também, contribuir para a avaliação dos efeitos do emprego de materiais didáticos, programas e intervenções que visem a favorecer a construção de valores sociomorais, apontando se houve ou não progressos nesse sentido e em que medida.

Os dados obtidos nesta pesquisa sobre a mensuração dos valores de justiça, respeito, solidariedade e convivência democrática em crianças, adolescentes e professores de educação básica nos permitem evidenciar algumas tendências mais gerais dos resultados.

Em primeiro lugar, e como é esperado pela Psicologia do desenvolvimento aplicada à área da moralidade, os professores mostraram-se em níveis mais avançados de adesão aos valores que os adolescentes e estes mais que as crianças. As diferenças entre professores, por um lado, e crianças e adolescentes, por outro, foram muito mais acentuadas que entre essas duas últimas populações.

Outra constatação que pode ser feita é a de que a aquisição dos valores, entendida neste estudo pelo modo de adesão a eles em diferentes perspectivas sociais (egocêntrica, sociocêntrica e propriamente moral), mostrou uma progressão diferente para cada valor, sendo mais fácil para o valor de solidariedade, seguindo-se os valores de respeito e justiça, e mais difícil para o valor de convivência democrática. Ou seja, no valor de solidariedade, crianças e adolescentes alcançaram mais frequentemente o nível III em perspectiva social que nos demais valores, e os professores concentraram-se no nível IV, o que não aconteceu nos outros valores.

O valor mais difícil de ser alcançado pelas crianças e adolescentes numa perspectiva social descentrada, isto é, relacionada aos contratos sociais ou aos princípios morais, foi o de convivência democrática. Foi nele que, por um lado, crianças e adolescentes mostraram-se concentrados em nível II, aderindo ao valor ainda de modo egocêntrico, e professores mostraram-se em nível III, aderindo ao valor de modo sociocêntrico. Por outro lado, nesse valor, apareceu uma porcentagem não desprezível de crianças e adolescentes em contravalores, ou seja, assumindo posições não democráticas.

Para os professores, o valor que se mostrou mais difícil, ou seja, cujos níveis de adesão foram mais baixos, considerando as perspectivas sociais, foi o de justiça. Nesse valor, houve predominância do nível III, sociocêntrico, mas $6 \%$ de professores encontraram-se em nível II, adesão em perspectiva egocêntrica e, ainda, professores em contravalor, o que não aconteceu nos outros três valores. Essa dificuldade nos itens sobre justiça pode estar relacionada com as histórias localizadas 
na escola, cujos conteúdos versavam sobre a aplicação de penalidades e sobre o uso de regras escolares para alunos. Nessas situações, raramente as escolhas foram por alternativas que indicavam soluções pautadas nos valores de igualdade e equidade, ou mesmo o emprego de sanções por reciprocidade.

Finalmente, como tendência geral, destacamos que o nível IV de adesão aos valores, definido como aquele no qual se concentrariam as respostas pró-valor em perspectivas propriamente morais, foi muito ausente nos três grupos de participantes da pesquisa, sendo alcançado somente em um valor - solidariedade - e por professores.

Considerando esses resultados, podemos afirmar que somente os professores tenderam à maior adesão a um dos valores numa perspectiva propriamente moral; isto é, quando se adota um valor por uma motivação acima das normas sociais e que reside no reconhecimento da dignidade de todo e qualquer ser humano. Nesse caso, diz-se que uma pessoa tende à autonomia moral: assume valores que, por si mesma, reconhece como bons para si e para qualquer outra pessoa. Nossas crianças e adolescentes demonstram, nos valores avaliados, estar ainda longe da autonomia moral, o que indica a necessidade de interação com ambientes em que tais valores estejam presentes e sejam efetivamente vivenciados.

A construção de relações mais justas e respeitosas e dos valores sociomorais nelas inseridos são, sem dúvida, metas importantes para a educação, e a escola, dependendo da qualidade das interações estabelecidas em seu interior, constitui-se num local propício para que esse desenvolvimento ocorra, como visto na introdução deste trabalho. Nesse sentido, não está sendo desconsiderado o papel formativo da família; porém, sabemos que é no ambiente escolar que o sujeito irá conviver com o âmbito público (referindo-se ao coletivo), estabelecer relações de igualdade e conviver com a diversidade.

As escolas, quer queiram, quer não, influenciam de maneira significativa a formação moral das crianças e adolescentes, todavia nem todas o fazem na direção da autonomia. É impossível evitar mensagens que dizem respeito à moralidade, já que as relações intraescolares embasam-se em normas e comportamentos, fornecendo informações sobre o que é bom ou mau, certo ou errado.

Constatamos que valores como solidariedade, justiça, respeito e convivência democrática estão sempre presentes nos objetivos dos projetos político-pedagógicos e nas falas dos professores. Contudo, não basta um projeto para autonomia, é preciso oferecer um ambiente escolar que seja, efetivamente, propício para tal conquista.

A formação de personalidades éticas não ocorre por transmissão direta, nem é decorrente de um desenvolvimento maturacional, mas, sim, de um processo de construção nas interações do sujeito com o 
meio. Para que esse desenvolvimento ocorra, é necessário que a criança possa fazer experiências morais. A justiça, por exemplo, não se aprende apenas com lições ou teorias sobre o assunto, mas experimentando relações em que as regras são realmente necessárias e valem para todos, em que há a vivência de situações de justiça pautadas na igualdade e na equidade. O mesmo é válido para o respeito mútuo, o diálogo e a solidariedade. Nesse sentido, os resultados de nossa pesquisa, que mostram as crianças e adolescentes aderindo aos valores de modo egocêntrico ou, no máximo, sociocêntrico, pois dependente da imposição da autoridade e de regras rígidas, evidenciam a necessidade de que os valores sociomorais estejam presentes e sejam vivenciados nas relações sociais cotidianas para que sua necessidade seja legitimada pelas próprias crianças.

Vimos, desse modo, que os valores de justiça e convivência democrática foram mais difíceis de ser desenvolvidos na população estudada. Isso nos mostra quão pouco são experienciados no cotidiano da vida, seja na escola ou fora dela.

Além da vivência nos valores, é preciso refletir sobre as ações vividas e se sentir respeitado no ambiente em que se vive, ou seja, a moralidade precisa ser objeto de apropriação racional pelos estudantes e profissionais da escola bem como é preciso se sentir valorizado para querer agir bem.

A educação moral não se limita apenas à socialização, ou seja, não se restringe a um processo no qual se adotam formas sociais estabelecidas, mas é também concebida como um processo no qual se criticam algumas normas e, por isso, novas formas de conviver são pensadas e discutidas. Nessa perspectiva, a educação moral deve apreender o significado das normas que definem a vida social e também construir novos sentidos de vida. Contudo, para que isso efetivamente ocorra, é preciso que haja a vivência da cidadania no cotidiano das relações, que se desenvolva o pensar crítico, o julgar, a coordenação das perspectivas, a análise dos princípios e das ações, a reflexão sobre "como viver", ou seja, quem se quer ser.

Tudo isso é um trabalho sistemático que resulta difícil de se realizar fora da escola e que, em todo caso, deveria constituir uma de suas principais funções. Esse é o nosso convite e o desafio que lançamos às escolas que participaram desta pesquisa.

\section{REFERÊNCIAS}

ANDRADE, D. F.; TAVARES, H. R.; VALLE, R. C. Teoria da resposta ao item: conceitos e aplicações. São Paulo: Associação Brasileira de Estatística. Sinape 2000. Disponível em: <www.ufpa.br/ heliton/arquivos/LivroTRI.pdf.> Acesso em: 10 abr. 2015. 
ARAÚJO, U. F. Resolução de conflitos e assembleias escolares. Cadernos de Educação, Pelotas, n. 31, p. 115-131, jul./dez. 2008.

ARAÚJO, U. F.; ARANTES, V. The ethics and citizenships program: the Brazilian experience in moral education. Journal of Moral Education, v. 38, n. 4, p. 489-511, 2009.

ARAÚJO, U. F.; PUIG, J. M.; ARANTES, A. A. (Org.). Educação em valores: pontos e contrapontos. São Paulo: Summus, 2007.

BATAGLIA, P. U. R.; SHIMIZU, A. M.; LEPRE, R. M. A teoria de Kohlberg sobre o desenvolvimento do raciocínio moral e os instrumentos de avaliação de juízo e competência moral em uso no Brasil. Estudos de Psicologia, Natal, v. 15, p. 25-32, 2010.

BAUMAN, Z. 0 mal-estar da pós-modernidade. Rio de Janeiro: Jorge Zahar, 1998.

BRASIL. Ministério da Educação. Secretaria de Educação Fundamental. Parâmetros curriculares nacionais. Brasília, DF: MEC/SEF, 1998.

COLBY, A.; KOHLBERG, L. The measurement of moral judgment. New York: Cambridge University Press, 1987.

D'AUREA-TARDELI, D. A manifestação da solidariedade em adolescentes: um estudo sobre a personalidade moral. 2006. Tese (Doutorado em Psicologia do Escolar) - Instituto de Psicologia, Universidade de São Paulo, São Paulo, 2006.

D’AUREA-TARDELI, D. Solidariedade e projeto de vida: a construção da personalidade moral do adolescente. Campinas, SP: Mercado de Letras; Fapesp, 2011. (Educação e Psicologia em Debate).

FRICK, L. T. As relações entre os conflitos interpessoais e o bullying: um estudo nos anos iniciais do ensino fundamental de duas escolas públicas. 2011. 195f. Dissertação (Mestrado em Educação) - Faculdade de Ciências e Tecnologia, Universidade Estadual Paulista “Júlio de Mesquita Filho”, Presidente Prudente, 2011.

GIBBS, J. C.; ARNOLD, K. D. E.; BURKHART, J. E. Sex differences in the expression of moral judgement. Child Development, n. 55, p. 1040-1043, 1984.

GOERGEN, P. Educação moral: adestramento ou reflexão comunicativa? Educação \& Sociedade, Campinas, v. 22, n. 76, p. 147-174, out. 2001.

GOERGEN, P. Educação moral hoje: cenários, perspectivas e perplexidades. Educação \& Sociedade, Campinas, v. 28, n. 100, p. 737-762, 2007.

HEBERT, P. et al. Evaluating ethical sensitivity in medical students: using vignettes as an instrument. Journal of Medical Ethics, n. 16, p. 141-145, 1990.

KARINO, C. A.; ANDRADE, D. F. Entenda a Teoria de respostas ao item (TRI). Nota técnica. Brasília, DF: Inep, 2011.

KOHLBERG, L. Essays on moral development: the philosophy of moral development: moral stages and the idea of justice. San Francisco: Harper \& Row, 1981. v. I.

KOHLBERG, L. Psicología del desarrollo moral. Bilbao: Biblioteca de Psicología, Desclée de Brouwer, 1992.

LA TAILLE, Y. Moral e ética: dimensões intelectuais e afetivas. Porto Alegre: Artmed, 2006.

LA TAILLE, Y. Formação ética: do tédio ao respeito de si. Porto Alegre: Artmed, 2009.

LA TAILLE, Y.; MENIN, M. S. M. (Org.). Crise de valores ou valores em crise? Porto Alegre: Artmed, 2009. p. 152-184.

LIMA, T. J. S. Modelos de valores de Schwartz e Gouveia: comparando conteúdo, estrutura e poder preditivo. 2012. Dissertação (Mestrado em Psicologia) - Universidade Federal da Paraíba, João Pessoa, 2012.

LIND, G. Moral competence test. Disponível em: <www.uni-konstanz.de/ag-moral/mut/mjt-engl.htm>. Acesso em: 29 jun. 2015. 
LIPOVETSKY, G. O crepúsculo do dever: a ética indolor dos novos tempos democráticos. 4. ed. Lisboa: Dom Quixote, 2010.

LOMBARDI, J. C.; GOERGEN, P. Ética e educação: reflexões filosóficas e históricas. Campinas, SP: Autores Associados, 2005.

MARTINS, R. A.; SILVA, I. A. Valores morais do ponto de vista de professores do ensino fundamental e médio. In: LA TAILLE, Y.; MENIN, M. S. S. (Org.). Crise de valores ou valores em crise? Porto Alegre: Artmed, 2009. p. 185-198.

MENIN, M. S. S. Representações sociais de injustiça em adolescentes de escolas públicas e particulares. Psicologia da Educação, PUC-SP, n. 14/15, p. 239-264, 2002.

MENIN, M. S. S. Injustiça e escola: representações de alunos e implicações pedagógicas. In: TOGNETTA, L. R. P. Virtudes e educação: o desafio da modernidade. Campinas, SP: Mercado de Letras, 2007.

MENIN, M. S. S.; BATAGLIA, P. U. R.; MORO, A. Adesão ao valor de justiça entre crianças e adolescentes. Estudos em Avaliação Educacional, v. 24, n. 56, p. 18-47, set./dez. 2013.

MENIN, M. S. S. et al. Educação moral ou em valores nas escolas: concepções de educadores em escolas públicas brasileiras. In: ENCONTRO DE PESQUISA EM EDUCAÇÃO DA REGIÃO SUL, 8., 2010, Londrina. Anais... Londrina: Anped, 2010. p. 1-12.

PIAGET, J. O julgamento moral na criança. São Paulo: Mestre Jou, 1994 [1932].

REST, J. DIT Manual: manual for the defining issues test. Minneapolis: University of Minnesot, 1986.

SELMAN, R. L. The growth of interpersonal understanding: developmental understanding. New York: Academic Press, 1980.

SELMAN, R. L. et al. Assessing adolescent interpersonal negotiation strategies: toward the integration of structural and functional models. Developmental Psychology, v. 22, n. 4, p. 450-459, 1986.

SILVA, D. J. Ética, educação e desafios contemporâneos. In: REUNIÃO ANUAL DA ANPED, 33., Caxambu, MG, 2010. Anais... Caxambu: Anped, 2010. Disponível em: <www.anped.org. br/33encontro/internas/ver/trabalhos-gt17>. Acesso em: 10 ago. 2011.

SILVA, J. B. A escola enfrenta a violência: dos projetos às representações docentes. 2004. $210 f$. Dissertação (Mestrado em Educação) - Faculdade de Ciências e Tecnologia, Universidade Estadual Paulista "Júlio de Mesquita Filho", Presidente Prudente, 2004.

SPOSITO, M. P. Um breve balanço da pesquisa sobre violência escolar no Brasil. Educação e Pesquisa, São Paulo, v. 27, n. 1, p. 87-103, jan./jun. 2001.

TAVARES, M. R. Avaliação de valores sociomorais: procedimentos para a construção de uma escala. Estudos em Avaliação Educacional, São Paulo, v. 24, n. 56, p. 252-272, set./dez. 2013.

TOGNETTA, L. R. P. A construção da solidariedade e a educação do sentimento na escola: uma proposta de trabalho com as virtudes numa visão construtivista. Campinas, SP: Mercado de Letras, 2003.

TOGNETTA, L. R. P. Sentimentos e virtudes: um estudo sobre a generosidade ligada às representações de si. 2006. 320f. Tese (Doutorado em Psicologia Escolar) - Instituto de Psicologia, Universidade de São Paulo, São Paulo, 2006.

TOGNETTA, L. R. P. Perspectiva ética e generosidade. Campinas, SP: Mercado de Letras, 2009.

TOGNETTA, L. R. P.; VINHA, T. P. Quando a escola é democrática: um olhar sobre a prática das regras e assembleias na escola. Campinas, SP: Mercado de Letras, 2007.

TREVISOL, M. T. C. Tecendo os sentidos atribuídos por professores do ensino fundamental ao médio profissionalizante sobre a construção de valores na escola. In: LA TAILLE, Y.; MENIN, M. S. M. (Org.). Crise de valores ou valores em crise? Porto Alegre: Artmed, 2009. p. 152-184.

VALLE, R. Construção e interpretação de escalas de conhecimento: um estudo de caso. Estudos em Avaliação Educacional, São Paulo, n. 23, p. 71-92, 2001.

VAZQUEZ, A. S. Ética. Rio de Janeiro: Civilização Brasileira, 1993. 
VICENTIN, V. F. Condições de vida e estilos de resolução de conflitos em adolescentes. 2009. 223f. Tese (Doutorado em Psicologia) - Instituto de Psicologia, Universidade de São Paulo, São Paulo, 2009.

VINHA, T. P. 0 educador e a moralidade infantil numa visão construtivista. Campinas, SP: Mercado de Letras, 2000.

VINHA, T. P. Os conflitos interpessoais na relação educativa. 2003. 426 f. Tese (Doutorado em Educação) - Faculdade de Educação, Universidade Estadual de Campinas, Campinas, 2003.

ZECHI, J. A. M. Violência e indisciplina em meio escolar: aspectos teórico-metodológicos da produção acadêmica no período de 2000 a 2005. 2008. 152 f. Dissertação (Mestrado em Educação) Faculdade de Ciências e Tecnologia, Universidade Estadual Paulista "Júlio de Mesquita Filho", Presidente Prudente, 2008.

\section{MARIALVA ROSSI TAVARES}

Pesquisadora da Fundação Carlos Chagas - FCC -, São Paulo, São Paulo, Brasil mtavares@fcc.org.br

\section{MARIA SUZANA DE STEFANO MENIN}

Professora titular da Universidade Estadual Paulista "Júlio de Mesquita Filho” - Unesp -, Presidente Prudente, São Paulo, Brasil; bolsista Produtividade em Pesquisa do Conselho Nacional de Desenvolvimento Científico e Tecnológico - PQ/CNPq sumenin@gmail.com

\section{PATRÍCIA UNGER RAPHAEL BATAGLIA}

Professora assistente doutora da Universidade Estadual Paulista "Júlio de Mesquita Filho" - Unesp -, Marília, São Paulo, Brasil

patriciaurbataglia@gmail.com

\section{TELMA PILEGGI VINHA}

Professora assistente doutora da Universidade Estadual de Campinas - Unicamp -, Campinas, São Paulo, Brasil

telmavinha@uol.com.br

\section{LUCIENE REGINA PAULINO TOGNETTA}

Professora assistente doutora da Universidade Estadual Paulista "Júlio de Mesquita Filho" - Unesp -, Araraquara, São Paulo, Brasil

lrpaulino@uol.com.br

\section{RAUL ARAGÃO MARTINS}

Professor Adjunto III da Universidade Estadual Paulista "Júlio de Mesquita Filho” - Unesp -, São José do Rio Preto, São Paulo, Brasil raul@ibilce.unesp.br

ADRIANO MORO

Assistente técnico de pesquisa da Fundação Carlos Chagas - FCC -, São Paulo, São Paulo, Brasil moroadriano@uol.com.br 